\title{
InterferênCIA das Plantas Daninhas na CULTURA da SOJ A CuLtivada EM DOIS ESPAÇAMENTOS ENTRE LINHAS ${ }^{1}$
}

\author{
Weed Interference in Soybean Crop Cultivated in Two Row Spacings
}

MELO, H.B. ${ }^{2}$, FERREIRA, L.R. ${ }^{3}$, SILVA, A.A. ${ }^{3}$, MIRANDA, G.V. ${ }^{3}$, ROCHA, V.S. ${ }^{3}$ e SILVA, C.M.M. ${ }^{2}$

\begin{abstract}
RESUMO - O presente trabalho teve como objetivo determinar o período anterior à interferência, o período total de prevenção da interferência e o período crítico de prevenção da interferência das plantas daninhas na cultura da soja, cultivar UFV-16, nos espaçamentos entre linhas de 30 e $60 \mathrm{~cm}$, mantendo-se uma população fixa de 400.000 plantas ha ${ }^{-1}$ nos dois espaçamentos. Os tratamentos foram constituídos de dois grupos: em um manteve-se a cultura na ausência de plantas daninhas em períodos iniciais após a emergência da cultura, e, no outro, a cultura foi mantida na presença de plantas daninhas em períodos iniciais após a emergência da cultura. Os períodos foram os seguintes: 0, 10, 20, 30, 40, 50 e 60 dias após a emergência, totalizando 14 tratamentos, dispostos em blocos casualizados, com quatro repetições. O período crítico de prevenção da interferência na soja, considerando a redução na produtividade de $2 \%$, localizou-se entre o $7^{\circ}$ e $5^{\circ}$ dia e o $18^{\circ}$ e $47^{\circ}$ dia para os espaçamentos de 30 e $60 \mathrm{~cm}$ entre linhas, respectivamente. Assim, para a soja cultivada em menor espaçamento entre linhas $(30 \mathrm{~cm})$, o controle das plantas daninhas deve ser iniciado mais cedo, quando comparado com espaçamento maior nas entrelinhas $(60 \mathrm{~cm})$.
\end{abstract}

Palavras-chave: controle, convivência, período crítico.

ABSTRACT - The objective of this work was to determine the period before interference, total period of interference, and critical period of weed interference in the soybean crop, cultivar UFV16 , sowed at 30 and $60 \mathrm{~cm}$ row spacing, maintaining the population in 400.000 plants ha in both row spacing treatments. The treatments comprised two groups, one group kept in the absence of weeds during the initial periods after crop emergence, and the other group kept in the presence of weeds during the same periods of the other group. The periods with and without weeds were: $0 ; 10 ; 20 ; 30 ; 40 ; 50$ and 60 days after crop emergence. The experiment consisted of 14 treatments, arranged in a randomized block design, with four replications. The soybean critical period of interference, considering a $2 \%$ crop yield reduction, occurred between the $7^{\text {th }}$ and $53^{\text {rd }}$ day and the $18^{\text {th }}$ and $47^{\text {th }}$ day after soybean emergence, for the spacing of 30 and $60 \mathrm{~cm}$ between rows, respectively. Therefore, when soybean is cultivated using narrow-row spacing $(30 \mathrm{~cm})$, weed control must be initiated earlier, as compared to larger row spacing $(60 \mathrm{~cm})$.

Key words: weed control, co-habitation, critical period.

\section{INTRODUÇÃO}

Quando o objetivo é implantar programas de manejo de plantas daninhas, torna-se imprescindivel conhecer os períodos de convivência entre as plantas daninhas e a planta cultivada e as possiveis interferências.

Segundo Pitelli (1985), os fatores que influenciam o grau de interferência de uma

1 Recebido para publicação em 6/2/2001 e na forma revisada em 2/7/2001.

2 Mestrando do Departamento de Fitotecnia da UFV; ${ }^{3}$ Professores do Departamento de Fitotecnia da Universidade Federal de Viçosa - UFV, 36571-000 Viçosa-MG. 
planta infestante em uma cultura podem estar relacionados à comunidade infestante (composição específica, densidade e distribuição), à cultura (espaçamento, densidade e cultivar) e ao ambiente (solo, clima e práticas de manejo adotadas). Nesse processo interativo, os fatores mais facilmente controláveis, na prática, são a época e a extensão do período de convivência entre a cultura e as plantas daninhas. No que se refere ao tempo em que as espécies infestantes competem pelos fatores de crescimento com as plantas cultivadas, Kasasian \& Seeyave (1969) sugerem que o período inicial de competição mais importante englobe os primeiros 25 a $33 \%$ do ciclo vegetativo das culturas, porque até nesta fase ainda não há boa cobertura do solo pela maioria das plantas cultivadas.

O manejo das plantas daninhas é essencial para o desenvolvimento da soja e pode ser feito através de diversos métodos. É de fundamental importância o conhecimento do período apropriado para a realização desse manejo, ou seja, o período no qual a presença de plantas daninhas acarretará prejuízos posteriores. Dessa forma, procurou-se determinar o período anterior da interferência (PAI), o periodo total de prevenção da interferência (PTPI) e o período crítico de prevenção da interferência (PCPI) para a cultura da soja, cultivar UFV-16, nos espaçamentos de 30 e $60 \mathrm{~cm}$, estipulando-se uma perda aceitável de $2 \%$ na produtividade.

\section{MATERIAL E MÉTODOS}

Foram conduzidos dois experimentos com a cultura da soja cultivar UFV-16, nos espaçamentos de 30 e $60 \mathrm{~cm}$, no período de 04/12/97 a 14/04/98, num solo de textura franco-argilo-arenosa, no município de Coimbra-MG. Adotou-se o delineamento em blocos casualizados, com quatro repetições e 14 tratamentos, os quais foram constituídos de dois grupos complementares, segundo critérios de manejo com controle e com convivência das plantas daninhas com a cultura. No grupo com controle, a cultura permaneceu livre da interferência das plantas daninhas da emergência até diferentes períodos, em dias após a emergência (DAE), do seu ciclo de desenvolvimento $(0,10,20,30,40,50$ e 60). No grupo com convivência, a cultura permaneceu infestada com as plantas daninhas por diferentes períodos do seu ciclo de desenvolvimento $(0$, $10,20,30,40,50$ e 60 DAE).

As parcelas referentes ao experimento 1 (espaçamento de $30 \mathrm{~cm}$ entre linhas) eram constituídas de 14 fileiras de $4 \mathrm{~m}$ de comprimento, espaçadas de $30 \mathrm{~cm}$. A área total de cada parcela foi de $16,8 \mathrm{~m}^{2}$, e a área útil, de $5,4 \mathrm{~m}^{2}$ (seis fileiras centrais de $3 \mathrm{~m}$ de comprimento). No experimento 2 (espaçamento de $60 \mathrm{~cm}$ entre linhas), as parcelas tinham sete fileiras de soja de $4 \mathrm{~m}$ de comprimento, com área útil de $5,4 \mathrm{~m}^{2}$ (três fileiras centrais de $3 \mathrm{~m}$ de comprimento).

O preparo do solo constou de uma aração e duas gradagens 30 dias antes da instalação do experimento. Por ocasião da semeadura, realizou-se adubação no sulco, com $500 \mathrm{~kg} \mathrm{ha}^{-1}$ da fórmula 4-14-8. Após a mistura do adubo com o solo no sulco, fez-se a semeadura em profundidade média de $3 \mathrm{~cm}$. O cultivar utilizado foi o UFV-16, semeado manualmente, distribuindo-se 18 e 36 sementes por metro de sulco, nos espaçamentos de 30 e $60 \mathrm{~cm}$, respectivamente. Após o desbaste, foram deixadas 12 e 24 plantas por metro de fileira, espaçadas de 30 e $60 \mathrm{~cm}$, obtendo-se uma população estimada de 400.000 plantas ha-1.

Para verificação dos efeitos dos tratamentos, avaliaram-se a ocorrência $\left(\mathrm{n}^{\mathrm{o}} \mathrm{m}^{-2}\right)$ e a biomassa seca $\left(\mathrm{g} \mathrm{m}^{-2}\right)$ de plantas daninhas, a altura de planta de soja e da inserção da primeira vagem, o peso de 100 sementes e a produtividade da cultura.

As épocas das determinações da ocorrência e da biomassa seca de plantas daninhas foram de acordo com os dois grupos de tratamentos. No grupo com controle, as avaliações foram realizadas aos $60 \mathrm{DAE}$ da soja. No grupo com convivência, as avaliações foram realizadas nos diferentes períodos do ciclo de desenvolvimento (10, 20, 30, 40, 50 e 60 DAE). Para estas determinações, foram realizadas coletas das plantas daninhas, por meio de três amostragens, ao acaso, na área útil das parcelas, utilizando-se quadrados de 30 x $30 \mathrm{~cm}$. Após cada avaliação, as plantas daninhas foram separadas por espécie, contadas $\left(\mathrm{n}^{\circ} \mathrm{m}^{-2}\right)$ e submetidas à secagem em estufa a $72 \pm 1{ }^{\circ} \mathrm{C}$, até peso constante, quando se determinou a biomassa seca $\left(\mathrm{g} \mathrm{m}^{-2}\right)$. 
A colheita foi realizada na área útil das parcelas, de forma manual, quando a soja atingiu o estádio R8, segundo escala de Fehr et al. (1971).

A análise de variância foi feita separadamente, segundo os critérios com controle e com convivência das plantas daninhas na cultura. Com a finalidade de ajustar as curvas de produtividade nesses períodos, foi realizada a análise de regressão. O modelo da análise de regressão adotado foi devido à análise biológica e significância do quadrado médio da regressão e dos coeficientes de regressão. A determinação do período anterior à interferência (PAI), do período crítico de prevenção da interferência (PCPI) e do período total de prevenção da interferência (PTPI) foi feita estimando-se perdas de $2 \%$ em relação ao valor da produtividade da testemunha capinada, segundo metodologia proposta por Cousens (1988), utilizando análise de regressão.

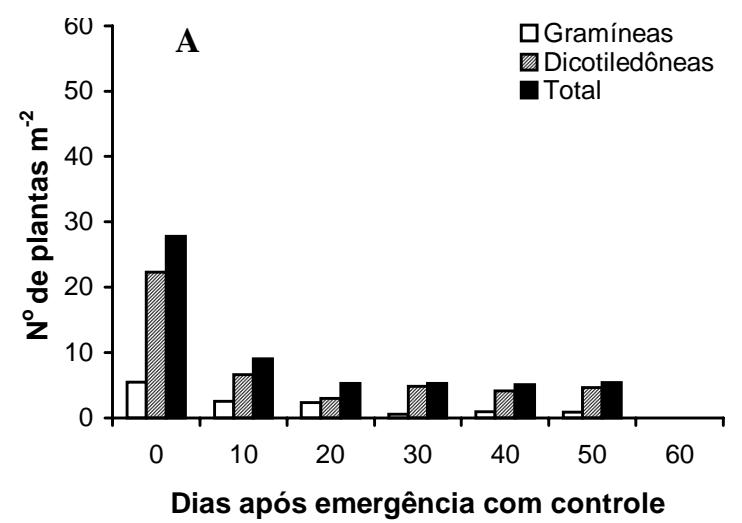

\section{RESULTADOS E DISCUSSÃO}

A ocorrência ( $\left.\mathrm{n}^{-} \mathrm{m}^{-2}\right)$ e a biomassa seca $\left(\mathrm{g} \mathrm{m}^{-2}\right)$ das plantas daninhas, agrupadas em gramíneas, dicotiledôneas e total de plantas daninhas, estão representadas nas Figuras 1 e 2, referentes ao espaçamento de $30 \mathrm{~cm}$, e Figuras 3 e 4 , referentes ao espaçamento de $60 \mathrm{~cm}$.

Verifica-se nas Figuras 1A e 3A maior ocorrência de dicotiledôneas em relação à de gramíneas. Comparando a ocorrência das plantas daninhas nos períodos de 10, 20, 30, 40, 50 e 60 dias após o primeiro cultivo, observou-se infestação praticamente constante. Este fato indica que ocorreu um fluxo inicial de emergência maior juntamente com a cultura da soja e que os demais fluxos foram muito pequenos.

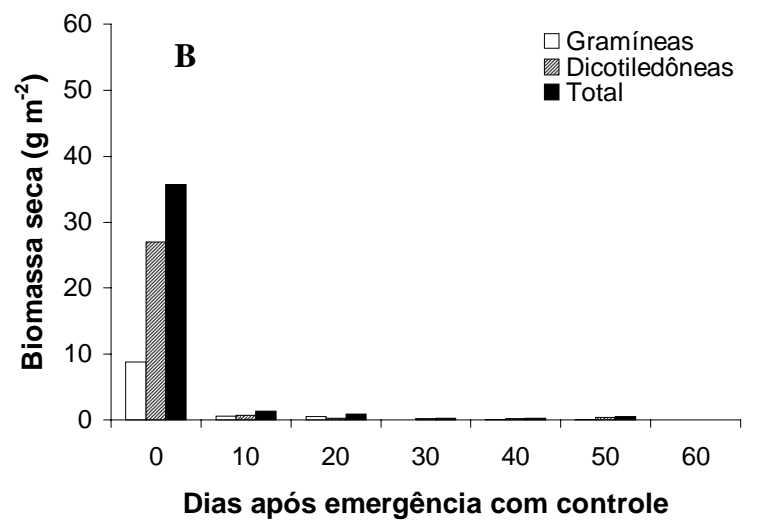

Figura 1 - Número médio (A) e biomassa seca (B) de gramíneas, dicotiledôneas e total de plantas daninhas aos 60 dias após emergência, em soja cultivada no espaçamento de $30 \mathrm{~cm}$ entre linhas, em função de diferentes períodos de controle. Viçosa, 1998.
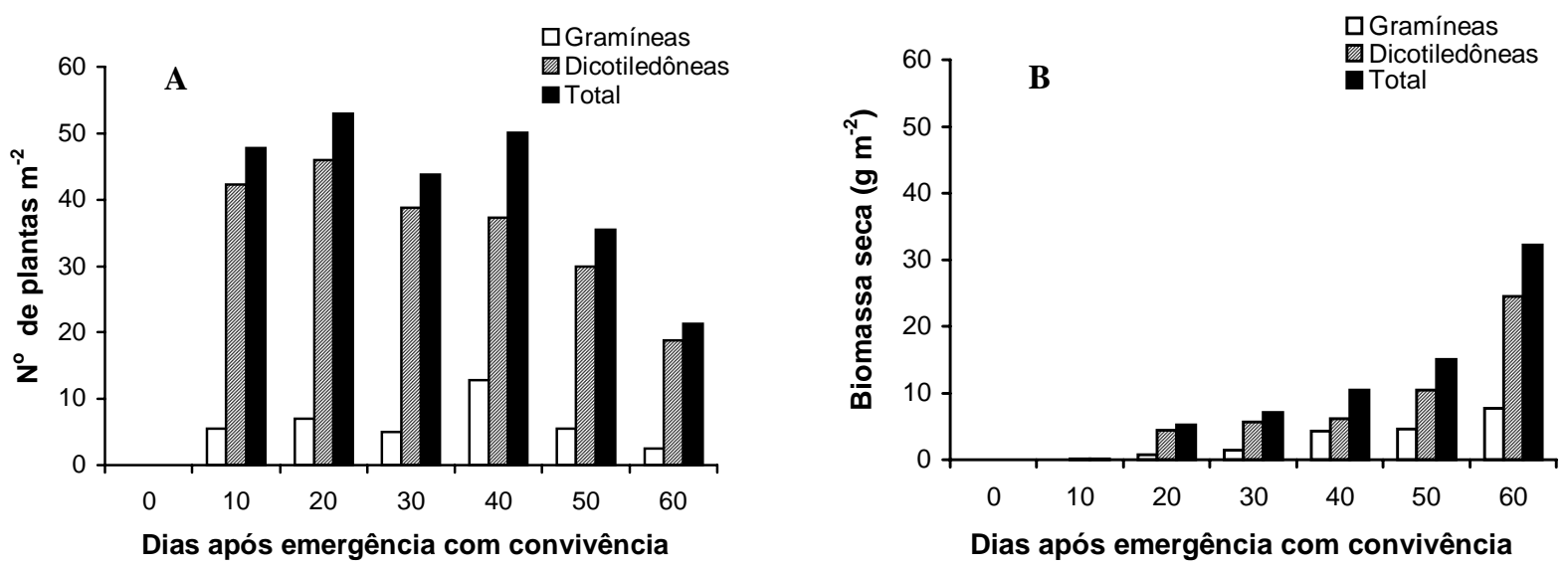

Figura 2 - Número médio (A) e biomassa seca (B) de gramíneas, dicotiledôneas e total de plantas daninhas, na cultura da soja cultivada no espaçamento de $30 \mathrm{~cm}$ entre linhas, observados nos diferentes períodos de convivência. Viçosa, 1998. 

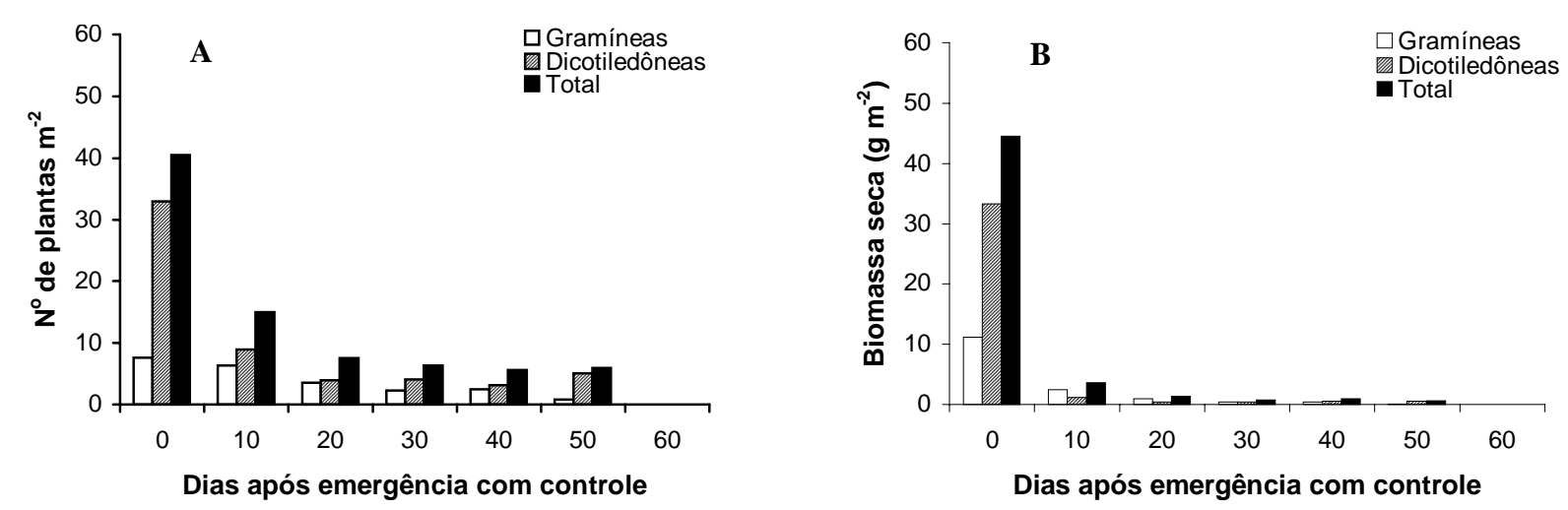

Figura 3 - Número médio (A) e biomassa seca (B) de gramíneas, dicotiledôneas e total de plantas daninhas aos 60 dias após emergência, em soja cultivada no espaçamento de $60 \mathrm{~cm}$ entrelinhas, em função de diferentes períodos de controle. Viçosa, 1998.
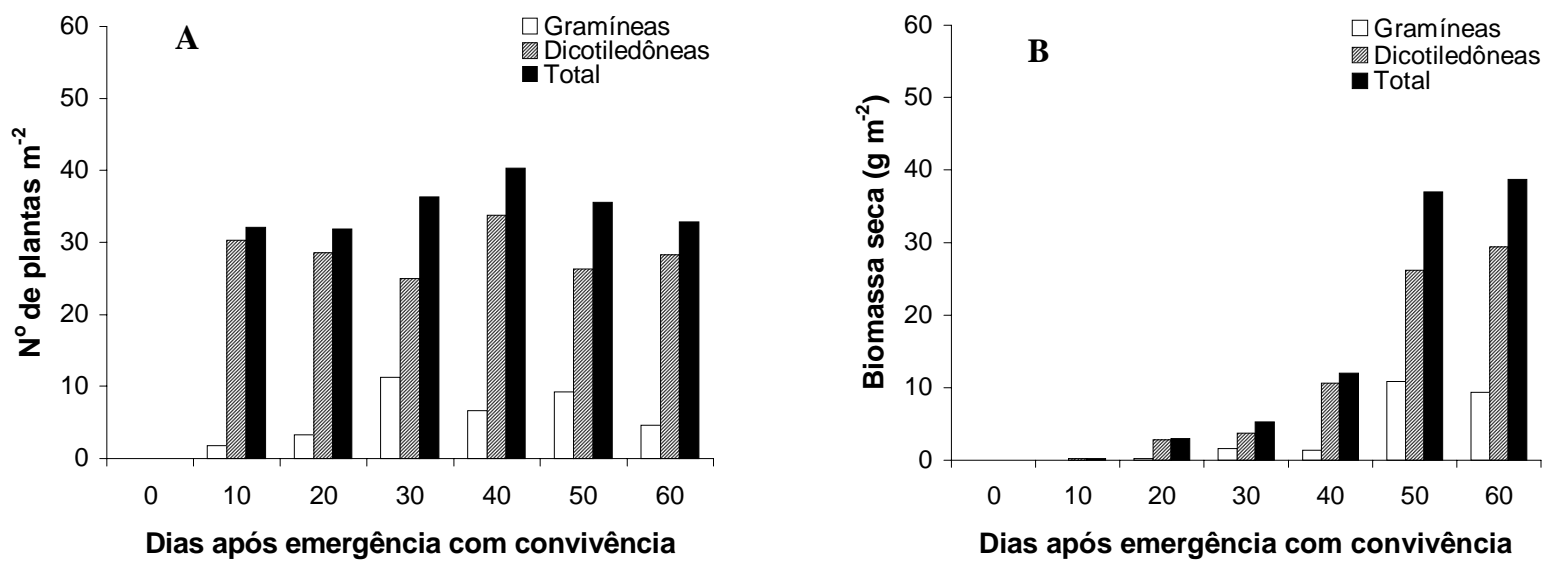

Figura 4 - Número médio (A) e biomassa seca (B) de gramíneas, dicotiledôneas e total de plantas daninhas, na cultura da soja cultivada no espaçamento de $60 \mathrm{~cm}$ entre linhas, observados nos diferentes períodos de convivência. Viçosa, 1998.

Guando se avaliou a ocorrência das plantas daninhas durante períodos de convivência (Figura 2A), observou-se que até $40 \mathrm{DAE}$ o número de plantas daninhas por metro quadrado permaneceu praticamente constante, decrescendo a partir dos 50 DAE. Este comportamento diferencia-se do observado no espaçamento de $60 \mathrm{~cm}$ (Figura 4), no qual o número de plantas daninhas se manteve aproximadamente constante no período com convivência, o que se deve ao fato de no espaçamento maior $(60 \mathrm{~cm})$ a pressão competitiva ter sido menor. Durigan et al. (1983) afirmam que vários são os fatores que influenciam a competitividade, e, dentre estes, encontra-se o espaçamento da cultura.

Quanto à matéria seca acumulada pelas plantas daninhas, observa-se nas Figuras 1B e $3 B$ que, quando se manteve a cultura sem concorrência no período de 10 a $50 \mathrm{DAE}$, os valores mantiveram-se próximos de zero. Todavia, quando a cultura ficou com convivência de plantas daninhas no período de 10 a $60 \mathrm{DAE}$ (Figuras 2B e 4B), essa biomassa seca aumentou, indicando que, embora o número das espécies infestantes tenha diminuído (Figura 2A) ou permanecido constante (Figura 4A), as plantas daninhas apresentaram maior crescimento vegetativo. Spadotto et al. (1992) observaram tendência semelhante, em que o acúmulo total de biomassa seca das plantas daninhas manteve-se em níveis baixos até certo período inicial de competição (20 a 30 dias), após o que ocorreu grande incremento. Estes mesmos autores verificaram que a importância de cada espécie isoladamente, como elemento competitivo, foi pequena, devido provavelmente a interações dentro da comunidade vegetal infestante, importando a resultante destas relações interativas para efeito de interferência na cultura. 
Embora não sejam apresentados os resultados da altura das plantas e da inserção da primeira vagem e do peso de 100 sementes, estas características não foram influenciadas pela presença das plantas daninhas na cultura.

A representação gráfica dos tratamentos (períodos com controle e com convivência de plantas daninhas com a cultura da soja) é mostrada na Figura 5. Observou-se redução na produtividade da soja em todos os períodos de convivência soja-planta daninha.

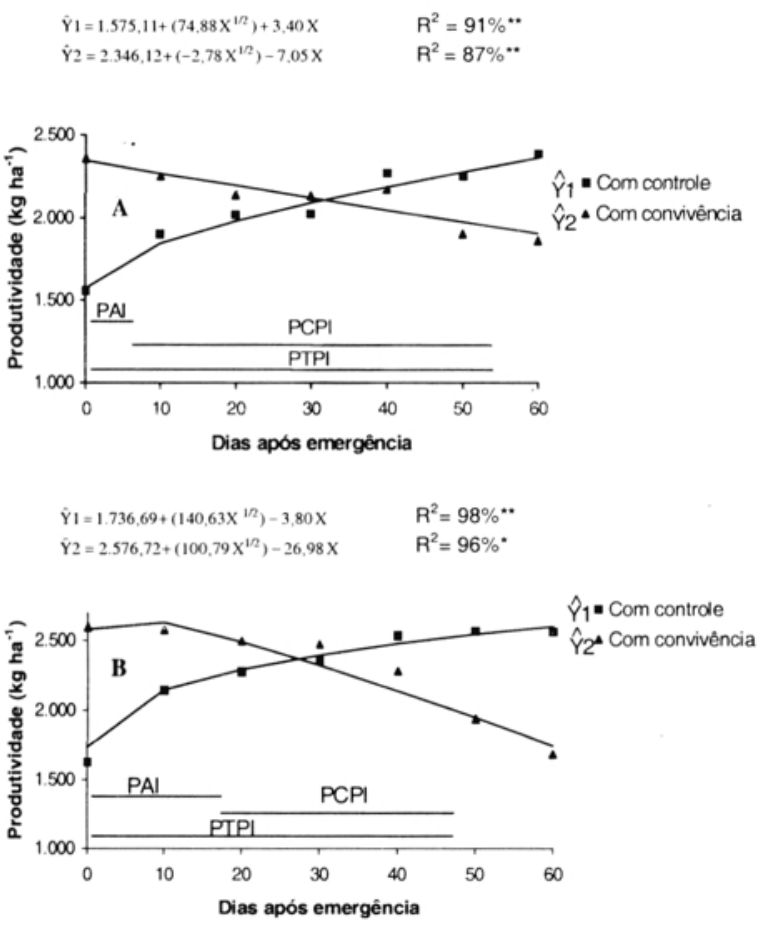

Figura 5 - Representação do PAI, do PCPI e do PTPI, estimando-se redução de $2 \%$ na produtividade da soja, nos espaçamentos de $30 \mathrm{~cm}$ (A) e $60 \mathrm{~cm}$ (B), segundo critérios de manejo com controle e com convivência das plantas daninhas. Viçosa, 1998.

Considerando como aceitável a perda (redução na produtividade) de $2 \%$ em relação à testemunha com capina, para a soja cultivada no espaçamento de $30 \mathrm{~cm}$ entre fileiras o PAI foi de 7 dias, o PTPI de 53 dias e o PCPI de 7 a 53 dias (Figura 5A). Para o espaçamento de $60 \mathrm{~cm}$ o PAI foi de 18 dias, o PTPI de 47 dias e o PCPI de 14 a 47 dias (Figura 5B). A interferência das plantas daninhas sobre culturas agrícolas é função de diversos fatores ligados à comunidade vegetal infestante, à cultura, ao ambiente e ao período de convivência (Pitelli, 1985). Devido ao grande número de fatores envolvidos, os resultados de pesquisa sobre a interferência de plantas daninhas em culturas são bastante variados. A ocorrência de menor PCPI no espaçamento de $60 \mathrm{~cm}$ contradiz Rodrigues (1985), que afirma que o período crítico para o manejo das plantas daninhas na cultura da soja estende-se até a época do fechamento da cultura, sendo esta mais cedo nos espaçamentos menores $(25-30 \mathrm{~cm})$. Entretanto, outros fatores, além do espaçamento entre linhas da cultura, estão relacionados com a interferência, podendo-se citar a distribuição das plantas daninhas, a composição específica e o arranjo populacional da cultura na área (Pitelli, 1985), podendo estes estar relacionados com o resultado obtido.

\section{LITERATURA CITADA}

DURIGAN, J.C.; VICTORIA FILHO, R.; MATUO, T.; PITELLI, R.A. Períodos de matocompetição na cultura da soja (Glycine max (L.) Merrill), cultivares Santa Rosa e IAC-2. II- Efeitos sobre características morfológicas das plantas e constituição química dos grãos. Planta Daninha, v.6, n.2, p.101-114, 1983.

COUSENS, R. Misinterpretations of results in weed research through inappropiate use of statistics. Weed Res., v.28, n.4, p.281-289, 1988.

FEHR, W.R.; CAVINESS, C.E.; BURMOOD, D.T.; PENNIGTON, J.S. Stage of development descriptions for soybeans, Glycine $\max (\mathrm{L}$.$) Merril.$ Crop Sci., v.11, n.4, p.929-931, 1971.

KASASIAN, L.; SEEYAVE, J. Critical periods for weed competition. PANS, v.15, n.2, p.208-212, 1969.

PITELLI, R.A. Interferência de plantas daninhas em culturas agrícolas. Inf. Agropec., Belo Horizonte, v.11, n.129, p.16-27, 1985.

PITELLI, R.A.; DURIGAN, J.C. Terminologia para periodos de controle e de convivência das plantas daninhas em culturas anuais e bianuais. In: CONGRESSO BRASILEIRO DE HERBICIDAS E PLANTAS DANINHAS, 15, Belo Horizonte. Resumos... Belo Horizonte: SBHED, 1984. p.37.

RODRIGUES, B.N. Utilização de herbicidas em plantio direto. In: FANCELLI, A.L., Coord. Atualização em plantio direto. Campinas: Fundação Cargill, 1985. p.51-85.

SPADOTTO, C.A.; MARCONDES, D.A.S.; LUIZ, A.J.B.; SILVA, C.A.R. Determinação do período crítico para prevenção da interferência de plantas daninhas na cultura da soja: Uso do modelo "Broken-Stick". Planta Daninha, v.12, n.2, p.5962, 1992. 